\title{
Identification of PTEN mutations in metastatic melanoma specimens
}

\author{
Julide Tok Çelebi, Igor Shendrik, David N Silvers, Monica Peacocke
}

\begin{abstract}
Context-PTEN, a tumour suppressor gene located on chromosome 10q23, develops somatic mutations in various tumours and tumour cell lines including brain, endometrium, prostate, breast, kidney, thyroid, liver, and melanoma.

Objectives-To investigate the mutational profile of this gene further, as well as its role in tumour progression in melanoma. Design, Settings-We examined 21 metastatic melanoma samples for $10 \mathrm{q} 23$ allelic losses and PTEN sequence alterations. Additionally, we screened these samples for mutations in $C D K N 2 A$, a gene in which alterations are well documented in primary melanoma as well as in the germline of familial melanoma.

Results-Loss of heterozygosity (LOH) at 10 q23 was observed in $33 \%(7 / 21)$ of the samples tested. We identified four sequence alterations in PTEN (19\%) and two in $C D K N 2 A(9.5 \%)$. Of interest, only one case showed mutations in both genes.

Conclusions-These data support the notion that PTEN alterations occur in some metastatic melanomas, and that mutation of this gene plays a role in the progression of some forms of melanoma.

(F Med Genet 2000;37:653-657)
\end{abstract}

Keywords: PTEN; CDKN2A; melanoma

A tumour suppressor gene, PTEN (also known as $M M A C 1$ or TEP1), was isolated by mapping homozygous deletions on human chromosome 10q23 from glioblastoma, prostate, and breast cancer cell lines. ${ }^{1-3}$ Subsequently, a series of mutations in PTEN were identified in sporadic tumours and cancer cell lines from various tissues including brain, endometrium, prostate, breast, kidney, thyroid, liver, and melanoma. ${ }^{4-11}$ Among all these tumours, PTEN is mutated with a high frequency in advanced stages of gliomas and prostate cancers, and in all stages of endometrial cancers. ${ }^{45^{12} 13}$ Furthermore, this tumour suppressor gene has been found to be the susceptibility gene for an inherited hamartoma syndrome with an increased risk of malignancy, Cowden syndrome (CS). ${ }^{14-18}$ Of interest, while breast and thyroid cancers are the most commonly observed tumours in CS, an increased risk of melanoma has not been documented in these patients.

PTEN is a phosphatase containing 403 amino acids. It is encoded by nine exons. The phosphatase catalytic domain is between the residues 122-132. Additionally, two potential phosphate acceptor sites are present at residues
233-240 and 308-315. ${ }^{2}$ The sporadic and germline mutations in PTEN cluster within the presumptive catalytic domain, with many mutations altering residues required for enzymatic activity. ${ }^{19}$ Recent studies show that PTEN modulates cell cycle progression and cell survival by regulating phosphoinositide-3kinase (PI3K) and the protein-Ser/Thr kinase (AKT) signalling pathway. ${ }^{20-22}$

Loss of heterozygosity ( $\mathrm{LOH}$ ) studies in melanoma have shown a high frequency of loss of $10 \mathrm{q} .{ }^{23-26}$ Several studies suggested involvement of chromosome 10q22-10qter in melanoma, ${ }^{27}$ as well as $10 \mathrm{q} 24-26$ in benign melanocytic proliferations, such as compound and dysplastic naevi. ${ }^{26}{ }^{28}$ After the isolation of PTEN from cancer cell lines harbouring homozygous deletions in 10q23, melanoma cell lines and uncultured primary and metastatic melanoma samples were examined for deletions or mutations in PTEN. To date, most of the data showing sequence alterations of PTEN are from studies using melanoma cell lines and not primary tumour samples. The most common alterations identified are homozygous deletions. ${ }^{8}$ Of interest, the reported incidence of point mutations and deletions in PTEN is significantly low for uncultured melanomas (approximately 10\%) when compared to tumour cell lines (approximately $29-43 \%$ ).

In addition to $10 \mathrm{q}, \mathrm{LOH}$ in melanoma has been observed in a number of different loci including $1 \mathrm{p}, 3 \mathrm{p}, 3 \mathrm{q}, 6 \mathrm{q}, 9 \mathrm{p}, 9 \mathrm{q}, 11 \mathrm{q}, 13 \mathrm{q}, 17 \mathrm{p}$, $17 q$, and $22 q .{ }^{23}$ Of these loci, $9 p$ shows high frequency of allelic loss in melanoma. Alterations in $C D K N 2 A$ located on $9 \mathrm{p} 21$ have been well documented in melanoma. ${ }^{29} 30$ Moreover, germline mutations in $C D K N 2 A$ have been identified in $9 \mathrm{p} 21$ linked familial melanoma cases. $^{31}{ }^{32} C D K N 2 A$ regulates cell cycle at the $\mathrm{G} 1$ to $\mathrm{S}$ transition by inhibiting CDK 4 and CDK6. Alterations in CDK4 have also been identified in melanoma, but appear to be rare..$^{33} 34$

In an attempt to investigate the role of somatic mutations of PTEN in metastatic melanoma and to understand its role in tumour progression further, we screened 21 sporadic metastatic melanoma samples for $\mathrm{LOH}$ at 10q23 and for mutations in the PTEN gene. All samples were subjected to direct sequencing analysis of the PTEN gene regardless of $\mathrm{LOH}$ data. In addition, the samples were also screened for $\mathrm{LOH}$ at $9 \mathrm{p} 21$ and for mutations in the $C D K N 2 A$ gene to determine whether these two tumour suppressor genes act independently or synergistically in the tumour progression of melanomas.
17 April 2000

Accepted for publication 1

May 2000 
A

$10 \mathrm{q} 23$

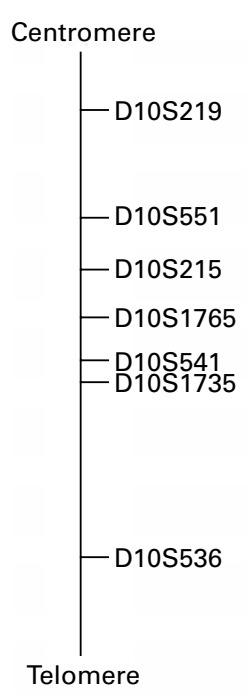

B
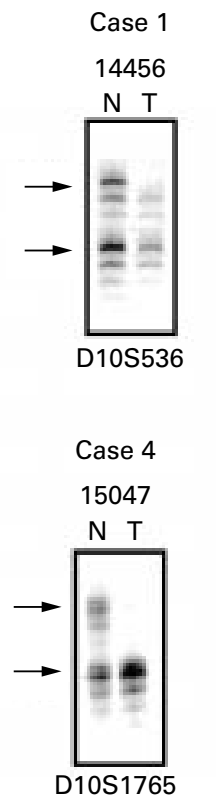
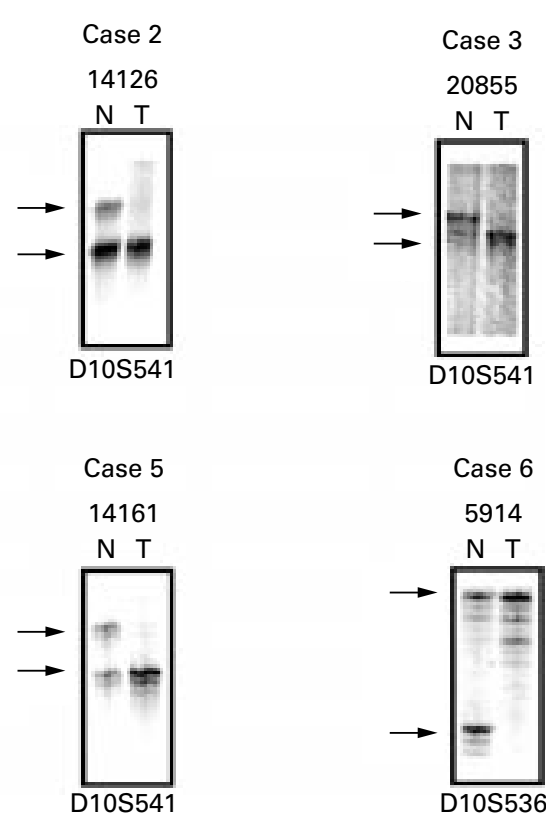

Figure 1 Loss of heterozygosity analyses of metastatic melanomas on chromosome 10q23. (A) Seven short tandem polymorphic repeat markers around the PTEN locus on $10 q 23$ used in this study. (B) Allele losses of cases 1-6 on 10q23 are shown. N: normal tissue; T: tumour tissue.

\section{Materials and methods}

TUMOUR SPECIMENS AND DNA PREPARATION A total of 21 metastatic melanoma samples in paraffin embedded blocks were obtained. Each tumour was examined histopathologically. All tumour samples contained greater than 70$80 \%$ tumour cells. A $15 \mu$ section was cut for each sample to be tested. The normal and tumour tissues were dissected out and placed separately into $1.5 \mathrm{ml}$ Eppendorf tubes. Total genomic DNA was purified from the deparaffinised section using a QIAamp Tissue Kit (Qiagen, Stanford, CA).

LOH ANALYSIS

$\mathrm{LOH}$ analysis was performed as described previously. ${ }^{35}$ The following seven polymorphic short tandem repeat microsatellite markers located on $10 \mathrm{q}$, in the interval known to contain the PTEN gene and its flanking regions, were used in this study: D10S219, D10S551, D10S215, D10S1765, D10S541, D10S1735, D10S17564, and D10S536 (fig 1A). Additionally, to look for $\mathrm{LOH}$ on $9 \mathrm{p}$, in the region containing the $C D K N 2 A$ gene and adjacent flanking regions, the following five microsatellite markers were used: D9S169, D9S171, D9S52, D9S178, and D9S492. LOH was assessed by quantitatively comparing polymorphic marker amplicons generated from tumour and normal DNA of each subject tested.

MUTATION SCREENING FOR PTEN AND CDKN2A

Nested PCR was performed for PTEN as described. ${ }^{2}$ For $C D K N 2 A$, we used the following primers flanking the coding sequence and the splicing sites. The forward ( $\mathrm{f}$ ) and reverse (r) primers used for amplification of CDKN $2 A$ were as follows. For exon 1, e1f1: 5'GAA GAAAGAGGAGGGGCT3'，e1r1： 5'GCGC TACCTGATTCCAATTC3', e1f2: 5'GGC
TGGTCACCAGAGGGTGG3', e1r2: 5' AG AGTCGCCCGCCATCCCCT 3'. For exon 2, e2f1: 5'GGAAATTGGAAACTGGAAGC3', e2r1: 5'TTTGGAAGCTCTCAGGGTAC3', e2f2: 5'TGGCTCTGACCATTCTGTTC3', e2r2: 5'TCAGATCATCAGTCCTCACC3'. For exon 3, e3f1: 5'CCGGTAGGGACG GCAAGAGA3', e3r1: 5'CTGTAGGACCCT CGGTGACTGATGA3'.

PCR products were sequenced using an Applied Biosystem 310 automated sequencing system. Sequence alterations were verified by sequencing the reverse strand, as well as by sequencing of a second DNA sample.

\section{Results}

DNA from 21 metastatic melanomas was screened for $\mathrm{LOH}$ using seven microsatellite markers on chromosome 10 near the PTEN locus (table 1). Regardless of LOH data, all tumour samples were then amplified with primers flanking the nine exons of the PTEN gene and sequenced to detect coding sequence or splice site variations. $\mathrm{LOH}$ and sequencing data are summarised in table 2 . Using this panel of markers, we observed LOH in seven cases $(7 / 21$, $33 \%$ ). All tumours, except case 7 , were informative for at least three markers in this region. No hemizygosity was observed in case 7 with all seven markers used. Of the seven samples with $\mathrm{LOH}$, five showed PTEN sequence alterations. The mutations consisted of a nonsense mutation in exon $6(633 \mathrm{C}>\mathrm{A})$ and two missense mutations in exons 1 (D19N) and 7 (V217I). Cases 4 and 5 showed LOH with at least two markers, but mutations by direct sequencing were not observed. In addition, two putative splice site changes in IVS1 $(79+14 \mathrm{G}>\mathrm{A})$ and IVS2 (165-13 G>A) were observed in cases 6 and 7 . These intronic sequence alterations have not been identified in 100 control samples. Overall, six of $21(28.5 \%)$ samples showed sequence 
Table 1 LOH analyses on chromosome 10q23 in metastatic melanoma

\begin{tabular}{|c|c|c|c|c|c|c|c|c|}
\hline \multirow[b]{2}{*}{ Case No } & \multirow{2}{*}{$\begin{array}{l}\text { Sample } \\
\text { No }\end{array}$} & \multicolumn{7}{|c|}{ Microsatellite markers (centromere $\rightarrow$ telomere) } \\
\hline & & D10S219 & D10S551 & D10S215 & D10S1765 & D10S541 & D10S1735 & D10S536 \\
\hline 1 & 14456 & o & o & o & - & + & - & + \\
\hline 2 & 14126 & - & + & o & + & + & - & o \\
\hline 3 & 20855 & o & + & o & - & + & + & - \\
\hline 4 & 15047 & o & - & - & + & o & - & - \\
\hline 5 & 14161 & + & - & o & - & + & - & o \\
\hline 6 & 5914 & o & + & o & - & + & o & + \\
\hline 7 & 4890 & o & o & o & o & o & o & o \\
\hline 8 & 23807 & - & - & o & - & o & - & - \\
\hline 9 & 359 & - & - & o & o & - & - & o \\
\hline 10 & 17974 & o & - & - & o & - & - & - \\
\hline 11 & 3260 & o & - & o & o & - & - & - \\
\hline 12 & 19529 & o & - & o & - & - & - & o \\
\hline 13 & 12917 & o & - & o & - & - & - & - \\
\hline 14 & 4789 & ND & o & - & - & - & o & - \\
\hline 15 & 8523 & ND & o & - & - & o & - & - \\
\hline 16 & 15374 & ND & o & - & NA & o & o & - \\
\hline 17 & 17146 & ND & - & - & - & o & - & o \\
\hline 18 & 5469 & ND & - & - & - & o & o & - \\
\hline 19 & 12714 & ND & NA & - & - & o & - & - \\
\hline 20 & 23151 & ND & o & - & - & o & - & - \\
\hline 21 & 24148 & ND & o & o & - & o & - & - \\
\hline
\end{tabular}

ND, not done; NA, no amplification; o, uninformative.

alterations when analysed by direct sequencing. Of interest, one tumour sample, case 8 , in which a missense mutation in exon $2(154 \mathrm{G}>\mathrm{A})$ was identified, did not show $\mathrm{LOH}$ with the panel of markers used.

Additionally, all samples were also tested for mutations in $C D K N 2 A$ by direct sequencing. We identified two missense mutations in cases 2 and $5(2 / 21,9.5 \%)$, both in exon 2 of $C D K N 2 A$. These two cases also show $\mathrm{LOH}$ at $9 \mathrm{p} 21$. Of these, case 2 showed sequencing variations both in PTEN and $C D K N 2 A$, whereas case 9 showed a nucleotide change in $C D K N 2 A$ only (table 2 ).

\section{Discussion}

To date, the information on mutational profile of PTEN in melanoma has been gathered primarily from studies using tumour cell lines and not primary tumour samples. These data show somatic mutations and deletions in $29-43 \%$ of the samples. ${ }^{8-10}$ Teng et at showed $48 \% \mathrm{LOH}$ at $10 \mathrm{q} 23$ in primary melanomas, in which only one missense mutation in PTEN $(10 \%)$ was identified. In the same study, they showed $50 \% \mathrm{LOH}$ in melanoma cell lines, and found four homozygous deletions (28\%). Guldberg et al ${ }^{9}$ studied melanoma cell lines and reported similar incidence of alterations (43\%) in PTEN. Of interest, in this study they showed that for three specimens identical alterations found in the cultured cell lines also existed in the uncultured tumour specimens. Finally,
Tsao et al $l^{10}$ described a mutation rate of $29 \%$ in melanoma cell lines, and $6 \%$ in uncultured metastatic melanomas. Of the uncultured metastatic melanomas they examined, only one showed a $7 \mathrm{bp}$ duplication in exon 7 leading to a premature stop codon. We have investigated uncultured metastatic melanomas for $\mathrm{LOH}$ at 10q23, and for alterations in PTEN and $C D K N 2 A$. In this set of 21 metastatic tumour samples, we detected $33 \%(7 / 21) \mathrm{LOH}$ at $10 \mathrm{q} 23$ and $28.5 \%(6 / 21)$ sequence alterations in PTEN by direct sequencing. CDKN2A mutations were encountered in $9.5 \%(2 / 21)$ of the samples tested. Only one case showed sequencing variations, both in PTEN and $C D K N 2 A$. These data support the notion that chromosomal alteration involving 10q23 and PTEN occur in metastatic melanoma.

The mutations of PTEN, both germline and somatic, have been reported in all nine exons of the gene. However, mutations in PTEN tend to cluster in exon 5, which contains the phosphatase catalytic domain. Aside from exon 5, a significant number of mutations have been observed in exons 6,7 , and 8 . Of the 21 samples analysed, we found one nonsense mutation in exon 6 and three missense mutations in exons 1, 2, and 7 in PTEN. All of the mutations identified in this study are novel somatic mutations in PTEN. Of interest, we observed the exon 6 mutation, C211X, in the germline of a family with Cowden syndrome (unpublished data). Additionally, we noted

Table 2 Summary of LOH on $10 q 23$ and mutations in PTEN compared to CDKN2A in metastatic melanoma

\begin{tabular}{|c|c|c|c|c|c|c|c|c|c|}
\hline \multirow[b]{2}{*}{$\begin{array}{l}\text { Case } \\
\text { No }\end{array}$} & \multirow[b]{2}{*}{$\begin{array}{l}\text { Sample } \\
\text { No }\end{array}$} & \multicolumn{4}{|c|}{ PTEN } & \multicolumn{4}{|c|}{$C D K N 2 A$} \\
\hline & & $\mathrm{LOH}$ & $\begin{array}{l}\text { Mutation/sequence } \\
\text { alteration }\end{array}$ & Predicted effect & $\begin{array}{l}\text { Exon or } \\
\text { IVS }\end{array}$ & $\mathrm{LOH}$ & $\begin{array}{l}\text { Mutation/sequence } \\
\text { alteration }\end{array}$ & $\begin{array}{l}\text { Predicted } \\
\text { effect }\end{array}$ & $\begin{array}{l}\text { Exon or } \\
\text { IVS }\end{array}$ \\
\hline 1 & 14456 & + & $633 \mathrm{C}>\mathrm{A}$ & $\mathrm{C} 211 \mathrm{X}$ & 6 & - & - & & \\
\hline 2 & 14126 & + & $55 \mathrm{G}>\mathrm{A}$ & $\mathrm{D} 19 \mathrm{~N}$ & 1 & + & $193 \mathrm{C}>\mathrm{T}$ & $\mathrm{L} 65 \mathrm{~F}$ & 2 \\
\hline 3 & 20855 & + & $649 \mathrm{G}>\mathrm{A}$ & V217I & 7 & ND & - & & \\
\hline 4 & 15047 & + & - & & & ND & - & & \\
\hline 5 & 14161 & + & - & & & + & $220 \mathrm{G}>\mathrm{A}$ & $\mathrm{D} 74 \mathrm{~N}$ & 2 \\
\hline 6 & 5914 & + & IVS $1+14 \mathrm{G}>\mathrm{A}$ & Putative splice site or polymorphism & IVS1 & ND & - & & \\
\hline 7 & 4890 & + & IVS2-13 G $>\mathrm{A}$ & Putative splice site or polymorphism & IVS1 & ND & - & & \\
\hline 8 & 23807 & - & $154 \mathrm{G}>\mathrm{A}$ & $\mathrm{D} 52 \mathrm{~N}$ & 2 & $\mathrm{ND}$ & - & & \\
\hline
\end{tabular}

$\mathrm{ND}$, not done. 
sequence alterations in PTEN in IVS1 $(+14$ $\mathrm{G}>\mathrm{A})$ and IVS2 $(-13 \mathrm{G}>\mathrm{A})$ in samples 6 and 7, which both also showed allelic loss of PTEN. These variations were not observed in 100 control sequences, thus suggesting that these intronic alterations may be either splice site changes resulting in exon skipping and thus a non-functional protein or rare polymorphisms in PTEN. To date, all of our studies of germline splice site alterations in CS have resulted in exon skipping, which suggests that this is likely to be the case here as well. ${ }^{18}$

It has been noted that mutations, both intragenic and homozygous deletions, in uncultured tumour tissue are detected with less sensitivity than in cell lines, because of heterogeneity within the sample, as well as normal stromal contamination. ${ }^{89}$ Most tumours are predicted to contain $10-40 \%$ normal cell contamination. Even 5\% normal DNA within a tumour can prevent identification of homozygous deletions using gel visualisation after $\mathrm{PCR}^{8}$ and thus homozygous deletions of uncultured specimens in PTEN have not been documented to date. Tumour tissue is also heterogeneous, so it is possible that only the most malignant cancer cells within a tumour may have detectable mutations. Similarly, mutations in tumour cell lines may be detected more easily because of the selection bias conferred in cells grown in cultures through multiple passages. For the reasons listed above, our results may be an under-representation of PTEN and CDKN2A mutations in metastatic melanoma. Despite the possibility of underestimation of mutations, our results and those reported previously suggest that $P T E N$ and $C D K N 2 A$ play a role in tumour progression in some, but not all, metastatic melanomas.

The authors acknowledge the technical support of Ya Juan Yao. Supported in part by grants from the National Cancer Institute (RO-1 CA-66693 and RO-1 CA-70519 to MP), the National RO-1 CA-66693 and RO-1 CA-70519 to MP), the National
Institute on Aging (K-04 AG-00694 to MP), and the National Institute on Aging (K-04 AG-00694 to MP), and the National Disease Research Center (PO-30 AR44535 to David R Bickers).

1 Li J, Yen C, Liaw D, Podsypanina K, Bose S, Wang SI, Puc J, Miliaresis C, Rodgers L, McCombie R, Bigner SH, Giovanella BC, Ittmann $M$, Tycko $B$, Hibshoosh H, Wigler MH, Parsons R. PTEN, a putative protein tyrosine phosphatase gene mutated in human brain, breast, and prostate cancer. Science 1997;275:1943-7.

2 Steck PA, Pershouse MA, Jasser SA, Yung WK, Lin $\mathrm{H}$, Ligon AH, Langford LA, Baumgard ML, Hattier T, Davis T, Frye C, Hu R, Swedlund B, Teng DH, Tavtigian SV. Identification of a candidate tumour suppressor gene, MMAC1, at chromosome $10 \mathrm{q} 23.3$ that is mutated in multiple advanced cancers. Nat Genet 1997;15:356-62.

$3 \mathrm{Li} \mathrm{DM}$, Sun H. TEP1, encoded by a candidate tumor suppressor locus, is a novel protein tyrosine phosphatase regulated by transforming growth factor beta. Cancer Res 1997; 57:2124-9.

4 Risinger JI, Hayes AK, Berchuck A, Barrett JC. PTEN/ MMAC1 mutations in endometrial cancers. Cancer Res 1997;57:4736-8.

5 Cairns P, Okami K, Halachmi S, Halachmi N, Esteller M, Herman JG, Jen J, Isaacs WB, Bova GS, Sidransky D. Frequent inactivation of PTEN/MMAC1 in primary prostate cancer. Cancer Res 1997;57:4997-5000.

6 Rhei E, Kang L, Bogomolniy F, Federici MG, Borgen PI, Boyd J. Mutation analysis of the putative tumor suppresso gene PTEN/MMAC1 in primary breast carcinomas. Cancer Res 1997;57:3657-9.

7 Dahia PL, Marsh DJ, Zheng Z, Zedenius J, Komminoth P, Frisk T, Wallin G, Parsons R, Longy M, Larsson C, Eng C. Somatic deletions and mutations in the Cowden disease gene, PTEN, in sporadic thyroid tumors. Cancer Res 1997; 57:4710-3.

8 Teng DH, Hu R, Lin H, Davis T, Iliev D, Frye C, Swedlund B, Hansen KL, Vinson VL, Gumpper KL, Ellis L, El-Naggar A, Frazier M, Jasser S, Langford LA, Lee J, Mills
GB, Pershouse MA, Pollack RE, Tornos C, Troncoso P,
Yung WK, Fujii G, Berson A, Steck PA. MMAC1/PTEN mutations in primary tumor specimens and tumor cell mutations in primary tumor specir

9 Guldberg P, Straten PT, Birck A, Ahrenkiel V, Kirkin AF, Zeuthen J. Disruption of the MMAC1/PTEN gene by deletion of mutation is a frequent event in malignant melanoma. Cancer Res 1997;57:3660.

10 Tsao H, Zhang X, Benoit E, Haluska FG. Identification of PTEN/MMAC1 alterations in uncultured melanomas and melanoma cell lines. Oncogene 1998;16:3397-402

11 Yao YJ, Ping XL, Zhang H, Chen FF, Lee PK, Ahsan H, Chen CJ, Lee PH, Peacocke M, Santella RM, Tsou HC. PTEN/MMAC1 mutations in hepatocellular carcinomas. Oncogene 1999;18:3181-5.

12 Suzuki H, Freije D, Nusskern DR, Okami K, Cairns P, Sidransky D, Isaacs WB, Bova GS. Interfocal heterogeneity of PTEN/MMAC1 gene alterations in multiple metastatic prostate cancer tissues. Cancer Res 1998;58:204-9.

13 Tashiro H, Blazes MS, Wu R, Cho KR, Bose S, Wang SI, Li J, Parsons R, Ellenson LH. Mutations in PTEN are frequent in endometrial carcinoma but rare in other common gynecological malignancies. Cancer Res 1997;57:3935-40.

14 Liaw D, Marsh DJ, Li J, Dahia PL, Wang SI, Zheng Z, Bose S, Call KM, Tsou HC, Peacocke M, Eng C, Parsons R. Germline mutations of the PTEN gene in Cowden disease, an inherited breast and thyroid cancer syndrome. Nat Genet 1997;16:64-7.

15 Tsou HC, Teng DH, Ping XL, Brancolini V, Davis T, Hu R, Xie XX, Gruener AC, Schrager CA, Christiano AM, Eng
C, Steck P, Ott J, Tavtigian SV, Peacocke M. The role of MMAC 1 mutations in early-onset breast cancer: causative in association with Cowden syndrome and excluded in BRCA1-negative cases. Am f Hum Genet 1997;61:1036-43.

16 Nelen MR, Staveren WCv, Peeters EA, Hassel MB, Gorlin RJ, Hamm H, Lindboe CF, Fryns JP, Sijmons RH, Woods DG, Mariman EC, Padberg GW, Kremer H. Germline mutations in the PTEN/MMAC1 gene in pate

17 Lynch ED, Ostermeyer EA, Lee MK, Arena JF, Ji H, Dann , Swisshelm K, Suchard D, MacLeod PM, Kvinnsland S, Gjertsen BT, Heimdal K, Lubs H, Moller P, King MC. Inherited mutations in PTEN that are associated with breast cancer, Cowden disease, and juvenile polyposis. $\mathrm{Am}$ f Hum Genet 1997;61:1254-60.

18 Tsou HC, Ping XL, Xie XX, Gruener AC, Zhang H, Nini R, Swisshelm K, Sybert V, Diamond TM, Sutphen R, Peacocke $M$. The genetic basis of Cowden's syndrome: three novel mutations in PTEN/MMAC1/TEP1. Hum Genet 1998;102:467-73.

19 Myers MP, Stolarov JP, Eng C, Li J, Wang SI, Wigler MH, Parsons R, Tonks NK. P-TEN, the tumor suppressor from human chromosome $10 \mathrm{q} 23$, is a dual-specificity phoshuman chromosome 10q23, is a dual-specificity

20 Myers MP, Pass I, Batty IH, Van der Kaay J, Stolarov JP, Hemmings BA, Wigler MH, Downes CP, Tonks NK. The lipid phosphatase activity of PTEN is critical for its tumour suppressor function. Proc Natl Acad Sci USA 1998;95: 13513-8.

21 Wu X, Senechal K, Neshat MS, Whang YE, Sawyers CL. The PTEN/MMAC1 tumor suppressor phosphatase functions as a negative regulator of the phosphoinositide 3-kinase/Akt pathway. Proc Natl Acad Sci USA 1998;95: 15587-91.

22 Sun $\mathrm{H}$, Lesche R, Li DM, Liliental J, Zhang H, Gao J, Gavrilova N, Mueller B, Liu X, Wu H. PTEN modulates cell cycle progression and cell survival by regulating phosphatidylinositol 3,4,5,-trisphosphate and Akt/protein kinase B signaling pathway. Proc Natl Acad Sci USA 1999;96: 6199-204.

23 Healy E, Rehman I, Angus B, Rees JL. Loss of heterozygosity in sporadic primary cutaneous melanoma. Genes Chrom Cancer 1995;12:152-6.

24 Healy E, Belgaid CE, Takata M, Vahlquist A, Rehman I, Rigby H, Rees JL Allelotypes of primary cutaneous melanoma and benign melanocytic nevi. Cancer Res 1996; 56:589-93.

25 Herbst RA, Weiss J, Ehnis A, Cavenee WK, Arden KC. Loss of heterozygosity for 10q22-10qter in malignant melanoma progression. Cancer Res 1994;54:3111-14.

26 Parmiter AH, Balaban G, Clark WH Jr, Nowell PC. Possible involvement of the chromosome region 10q24-q26 in early stages of melanocytic neoplasia. Cancer Genet Cytogenet 1988;30:313-17.

27 Walker GJ, Palmer JM, Walters MK, Hayward NK. A genetic model of melanoma tumorigenesis based on allelic losses. Genes Chrom Cancer 1995;12:134-41.

28 Richmond A, Fine R, Murray D, Lawson DH, Priest JH. Growth factor and cytogenetic abnormalities in cultured nevi and malignant melanomas. F Invest Dermatol 1986;86: 295-302

29 FitzGerald MG, Harkin DP, Silva-Arrieta S, MacDonald DJ, Lucchina LC, Unsal H, O'Neill E, Koh J, Finkelstein DM, Isselbacher KJ, Sober AJ, Haber DA Prevalence of germ-line mutations in p16, p19ARF, and CDK4 in familial melanoma: analysis of a clinic-based population. Proc Natl Acad Sci USA 1996;93:8541-5.

30 Monzon J, Liu L, Brill H, Goldstein AM, Tucker MA, From L, McLaughlin J, Hogg D, Lassam NJ. CDKN2A mutations in multiple primary melanomas. $N$ Engl $\mathcal{F}$ Med 1998;338:879-87.

31 Hussussian CJ, Struewing JP, Goldstein AM, Higgins PA, Ally DS, Sheahan MD, Clark WH Jr, Tucker MA, Draco-
poli NC. Germline p16 mutations in familial melanoma. Nat Genet 1994;8:15-21. 
32 Kamb A, Shattuck-Eidens D, Eeles R, Liu Q, Gruis NA, Ding W, Hussey C, Tran T, Miki Y, Weaver-Feldhaus J. Ding W, Hussey C, Tran T, Miki Y, Weaver-Feldhaus J.
Analysis of the p16 gene (CDKN2) as a candidate for the Analysis of the p16 gene (CDKN2) as a candidate for the
chromosome 9p melanoma susceptibility locus. Nat Genet chromosome

33 Zuo L, Weger J, Yang Q, Goldstein AM, Tucker MA, Walker GJ, Hayward N, Dracopoli NC. Germline mutations in the p16INK4a binding domain of CDK4 in familial melanoma. Nat Genet 1996;12:97-9.
34 Tsao H, Benoit E, Sober AJ, Thiele C, Haluska FG. Novel mutations in the p16/CDKN2A binding region of the cyclin- dependent kinase-4 gene. Cancer Res 1998;58:10913.

35 Steck PA, Hadi A, Cheong HC, Yung WKA, Pershouse MA. Evidence for two tumor suppressive loci on chromosome 10 involved in glioblastomas. Genes Chrom Cancer 1995;12: 255. 